\title{
OBSERVATIONS ON THE ORIGIN AND FATE OF FLAGELLATED GAMETES IN MULTIPLE TESTS OF DISCORBIS (FORAMINIFERA)
}

\author{
By Earl H. Myers, Ph.D. \\ John Simon Guggenheim Fellow
}

(Plates I-III)

\begin{tabular}{|c|c|c|c|c|c|c|c|c|c|}
\hline \multicolumn{10}{|c|}{ CONTENTS } \\
\hline Introduction & . & . & . & - & . & . & $\cdot$ & - & 201 \\
\hline Historical & . & . & . & . & . & . & 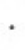 & . & 202 \\
\hline Material . & . & . & . & . & . & . & & & 203 \\
\hline Methods. & . & . & . & . & . & . & & & 205 \\
\hline Ecology . & . & . & . & . & . & . & 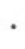 & & 207 \\
\hline $\begin{array}{l}\text { Life cycle } \\
\text { Gametes }\end{array}$ & . & . & . & . & . & . & & & $\begin{array}{l}209 \\
209\end{array}$ \\
\hline \multicolumn{3}{|c|}{ Sexual reproduction } & . & . & . & . & & & $2 \mathrm{I} 2$ \\
\hline \multirow{2}{*}{\multicolumn{5}{|c|}{ Metagamic nuclear divisions }} & . & . & & & 212 \\
\hline & & & & & . & . & & & 212 \\
\hline \multicolumn{6}{|c|}{ Development of microspheric test } & . & & & $2 \mathrm{I} 4$ \\
\hline Addition $\mathrm{c}$ & of a $x$ & new & cham & per & a test & . & & & 216 \\
\hline \multicolumn{6}{|c|}{ Nuclei of microspheric agamonts } & . & & & 216 \\
\hline \multicolumn{3}{|c|}{ Asexual reproduction } & . & . & . & . & & & 217 \\
\hline \multicolumn{3}{|c|}{ Division of nuclei } & . & . & . & . & . & & 217 \\
\hline Multiple $\mathrm{f}$ & & & . & . & . & . & & & 217 \\
\hline \multicolumn{3}{|c|}{ Development of th } & e gar & ont & . & . & . & & 218 \\
\hline \multirow{2}{*}{\multicolumn{3}{|c|}{$\begin{array}{l}\text { Syzygy . } \\
\text { Gametogenesis }\end{array}$}} & . & . & . & . & & & 219 \\
\hline & & & . & . & . & . & & $\cdot$ & 220 \\
\hline \multicolumn{7}{|c|}{ Comparative study of life cycles of Foraminifera } & - & * & 221 \\
\hline Conclusions & · & . & . & . & . & . & . & . & 223 \\
\hline \multicolumn{3}{|c|}{ Acknowledgements . } & . & . & . & . & - & $\cdot$ & 224 \\
\hline Summary & · & . & . & . & . & . & - & • & 224 \\
\hline & & . & . & . & . & . & - & • & 224 \\
\hline \multicolumn{4}{|c|}{ Explanation of Plates I-III } & . & . & . & . & . & 225 \\
\hline
\end{tabular}

\section{INTRODUCTION}

If one were to select three multiple tests of a Discorbis species of Foraminifera from material recently removed from a tide pool, and these groups, consisting of two or more individuals, were crushed in a drop of sea water under a coverglass, one would probably liberate a small cloud of minute flagellated organisms. Swarmers produced by a group of Foraminifera so associated are the gametes of the species. 
A demonstration based on incontrovertible evidence of the occurrence of flagellated gametes in the Foraminifera is important, first, because the small diameter of the amoebula that would result from the union of the gametes in sexual reproduction has been used to explain the small size of the proloculum or initial chamber of microspheric tests, compared with that of the cytologically proven megalospheric generation (Lister, I895, p. 444) and, secondly, these flagellated gametes might provide a brief pelagic phase that could assure a wide dispersal of reproductive bodies, and account in part for the geographic distribution of species (Vaughan, 1933, pp. 925-9). Perhaps the greatest value to be derived from a satisfactory solution of this problem would be to divert the attention of the biologist interested in the Foraminifera, from taxonomy, and the laborious task of proving or disproving dogmas which are inherent in the study of life-cycles, to problems of ecology, for it is only through knowledge of those factors which contribute to the success of species in recent oceans that we may hope to interpret biotic conditions in oceans of geologic horizons. Significant contributions in which the Foraminifera have been used as guides in this manner have been largely the work of geologists.

\section{HISTORICAL}

The possible occurrence of flagellated gametes in the Foraminifera was first discussed by Strethill Wright (I86I), after he had observed spermatozoalike organisms in Gromia. J. J. Lister (I895) first explained that where two distinct types of tests occurred within a recognized species, this dimorphism was the result of an alternation of generations, and the gametes were probably flagellated. The so-called gametes of Polystomella crispa Linn. (Elphidium) were observed in organisms less than half-grown, and Lister recognized that the cytological evidence of their origin was problematical. Later attempts to substantiate these findings have with few exceptions resulted in the description of flagellated organisms, presumably gametes, which might with equal conviction have been described as saprophytes, parasites, or commensals. In Patellina corrugata Williamson (Myers, I935) and Spirillina vivipara Ehrenberg (Myers, I936) the gametes were found to be amoebulae, not flagellated. In these two species it was demonstrated for the first time in the life cycle of a foraminiferan that all nuclei were the result of mitotic division and it seemed likely that the nuclei of all Foraminifera had a similar origin. Føyn (1936a), working on Myxotheca areniliga Schaudinn, and Calvez (1938) on Iridia lucida nov.sp. have since proposed life cycles in which the small nuclei of the gametes were the result of mitotic division. Except for a difference in the number of chromosomes represented there is a remarkable similarity in composition of stages illustrated in these two papers. Both authors have figured flagellated gametes in several species, but the only description of the development of a foraminiferan from flagellated gametes was that by Schaudinn (1903), which immediately followed a paper by Lister 
(I903) in which it was stated that although the life cycle of Polystomella crispa was generally accepted, the nature and fate of the "zoospore" had not been determined. Reproduction of Foraminifera that had previously associated in groups of two or more was reported by Schaudinn (1895) in Discorbina globularis d'Orbigny(?). Since he did not observe the gametes or the union of nuclei he presumed that this was a modified method of asexual reproduction. Had Schaudinn crushed several of these multiple tests, he undoubtedly would have found that about one group in three contained flagellated organisms, the gametes of the species. In a brief account of reproductive activities in groups of Foraminifera similarly associated, Myers (1933) described and gave photographic evidence of the occurrence of triflagellated organisms in Discorbis patelliformis Brady. Two-chambered young were also observed in multiple tests of the same species, but no cytological evidence as to the origin or fate of the flagellated gametes was given. The present paper demonstrates a genetic continuity of stages, through nuclear division, in the life cycle of several species of Discorbis in which the gametes are flagellated.

Groups of two or more free-living Foraminifera so associated that the several tests are contained within a common cyst, or are held together by animal cement, have been variously explained. Schaudinn (I895) presumed that such an association resulted in a modified method of asexual reproduction, as was stated above, and to which he applied the term "plastogamy". Rhumbler (1913) referred to a similar observation as "cytogamy", and HeronAllen (I9I5) suggested that these associated groups of tests were the result of reproduction by "budding". Since "plastogamy", "cytogamy", and "budding" in the sense that these terms were first applied to the Foraminifera do not suggest the sexual processes which occur within these groups of tests, we have applied the protozoological term "syzygy" to this method of sexual reproduction, and "multiple tests" to groups of two or more Foraminifera so associated (Myers, 1933 \& 1935).

\section{MATERIAL}

Multiple tests of several species of Discorbis, collected from tide pools during seven successive seasons, have yielded flagellated gametes and developmental stages of sexually produced young. In southern California Discorbis patelliformis Brady, and D. pulvinata Brady were common. From Monterey Bay north to San Francisco, D. ornatissima Cushman, and D. opercularis d'Orbigny occurred, the latter being especially abundant, and at Plymouth, England, D. parisiensis d'Orbigny was found.

$D$. patelliformis is a small, free, shallow-water representative of a numerous and widely distributed genus (Pl. I, figs. I-3; Pl. II, figs. 9-II). The test is smooth and conical, consisting of two or three convolutions of long narrow chambers. On the superior surface the chambers are marked by broad smooth lines, and perforated by depressed pseudopodial pores. The inferior surface 
is ornamented by radiating riblets provided with low tubercules which become short spines near the umbilicus. The subacute margin of the steeply sloping wall shows a clear line of shell substance which becomes increasingly thickened after the addition of each newly formed chamber. Although $D$. patelliformis is a dimorphic species, the average diameter of the microspheric and megalospheric proloculum or initial chamber does not vary appreciably, the only means of distinguishing the two types of tests being the direction of rotation of the series of chambers. Dimorphism in the Foraminifera is the result of an alternation of generations. In most species the sexually produced microspheric generation has a smaller initial chamber, a greater maximum size, and is multinucleate; while the asexually produced megalospheric generation shows a smaller growth limit, a larger initial chamber, and rarely more than one nucleus. Except for the size of the initial chamber the above characteristics hold for $D$. patelliformis, as evidenced from stained total mounts and several hundred tests removed from cultures immediately following either sexual or asexual reproduction; which left no doubt as to the accuracy of the observation that in this species the direction of rotation in the megalospheric test is sinistral, the microspheric dextral. A reversal in the direction of rotation of megalospheric and microspheric tests of other species studied show numerous exceptions to this rulẹ. In $D$. patelliformis no evidence in support of the theory of trimorphism was observed, either in the tests, or in a deviation from the normal method of sexual reproduction by megalospheric organisms. The ratio of microspheric to megalospheric individuals of this species in the sea during the month of July is about two to one.

D. opercularis is somewhat larger, and more depressed than D. patelliformis, the superior surface being more convex than conical. The lines marking the chambers are wider and free from pseudopodial pores, and the surface of the chambers is smooth. The inferior surface is flattened and ornamented by more widely spaced riblets and tubercules. The outer walls of earlier formed chambers are laminated, the clear shell substance along the acute margin of the test showing a graded increase in thickness beginning with the thin-walled terminal or final chamber. In life $D$. opercularis is yellowish pink, while $D$. patelliformis is bright orange red. The empty test of the former is cream white, while the latter retains a part of the original colour, due perhaps to residual cytoplasmic inclusions which remain in the test following reproduction.

D. ornatissima is more robust than the two species described above, the superior surface is subglobular, the peripheral edge subangular, and the inferior surface depressed, the sutures are neither limbate nor depressed, and on the ventral surface finely tuberculate riblets radiate from the umbilicus. Only the final convolution and the first few chambers show on the superior surface and numerous small pseudopodial pores open through the thick translucent walls.

D. pulvinata is a small, fragile, depressed and broadly ovate species, the 
final chambers being somewhat inflated. The inferior surface is deeply excavated and ornamented with radiating granulose lines.

It is interesting that the inferior surface of the tests of all species of Discorbis in which we have observed multiple tests should be ornamented by tuberculose or granulose riblets radiating from the umbilicus.

Active cultures of $D$. patelliformis and D. opercularis have been maintained on four occasions of from 3 months to I year (see Methods, below). Serial sections of more than 600 groups of organisms showing all phases of sexual reproduction, in addition to those showing asexual reproduction and developmental stages, were prepared from tide-pool and culture material. Since the notes on life activities of $D$. patelliformis, reared in cultures, are more complete, and the stained preparations of organisms from these cultures are free from annoying cytoplasmic inclusions, descriptions will be confined largely to this species. Except for specific characteristics and the number of nuclei in microspheric organisms, which determines the number of asexually produced young, the life cycles of $D$. patelliformis, $D$. opercularis, and $D$. ornatissima do not vary appreciably.

\section{METHODS}

In collecting species of Foraminifera in which multiple tests occur, handsful of coralline algae should be washed vigorously in a suitable container filled with sea water, provided with a piece of netting that will allow the finer sediments, including the Foraminifera, to settle to the bottom, while retaining the coarser materials. The sediments should be examined for multiple tests under the low power of the microscope, but should not be sorted if the material is to be used to start cultures. Best results were obtained by placing about one teaspoonful of the sediments in each of a number of 4 in. round-bottomed finger bowls filled with sea water recently removed from the sea. Each dish should be covered with a plate of glass to prevent excess evaporation, and the dish placed near a north window where the temperature will not exceed, by more than a few degrees, the average surface temperature in the sea during the summer months; $2 \mathrm{I}^{\circ} \mathrm{C}$. was found to be optimum at La Jolla, California. The water should be changed daily, or after several days, every other day, and maintained at a marked level, since many Foraminifera will move up the inclined wall of the dish and collect immediately below the meniscus. If after changing the water these organisms remain exposed they will not move downward into the water, even though the wall of the dish is wet. After a few days a favourable balance will become established. It is not advisable to remove the bits of algae or other debris, for to do so will usually upset this balance, and result in the loss of the culture. Larger organisms, especially annelids, should be removed, for certain of these feed upon small Foraminifera. If the water is not changed frequently the association of Foraminifera in sexual groups will usually result in the production of gametes, but further development should not be expected. Water from salt water systems should be avoided. 
No doubt more difficult methods would yield results, but by following this simple procedure we were able at times to remove from a single 4 in. dish from twenty to thirty groups of multiple tests per day, over a period of several weeks; one culture from which material had not been removed for several days contained I 28 doubles, three triples, and one group of four. We have maintained genetic cultures of other species of Foraminifera for many generations, but the length of the life span of most species is only one factor that should prevent many investigators from attempting work with pure cultures (Myers, 1937).

In the present investigation technical difficulties which resulted in poorly stained chromosomes and ill-defined achromatic figures were due perhaps to several causes. The small diameter of the pseudopodial pores and the aperture of the test prevented the rapid penetration of fixatives. There was also an unfavourable chemical reaction between most fixatives and the calcium carbonate of the outer walls and the septa of the test. Fixation by very hot as well as cooled solutions proved useful, but strongly acidified fixatives render this material useless for the study of division figures. The further hydrolysis of the chromatin by most fluids used to complete decalcification of the test further diminishes the capacity of the chromatin to react to stain. These factors, together with the problem of obtaining organisms in which the nuclei were in a state of division, may explain in part why various theories as to the origin of nuclei in Foraminifera have been proposed which are not in agreement with modern concepts of protozoan cytology. Isolated examples of mitotic division have been described and figured, but few of these will stand critical examination. In Patellina corrugata and Spirillina vivipara the rapid dissolution of the test and penetration of the delicate chitinous membrane by hot, strongly acidified fixatives acting only for a brief period may have obviated this difficulty. In the life cycles of Discorbis discussed in this paper it was possible to demonstrate an orderly progression of numbers of nuclei during the several periods of nuclear multiplication, and many preparations show evidence of spindles and chromosomes, but without sufficient definition to warrant the publication of drawings of a sequence of stages in nuclear division at this time.

Basophilic cytoplasmic inclusions often made it difficult to interpret cytological preparations of Foraminifera collected from tide pools, and occasionally caused annoyance in organisms reared in cultures. These inclusions consisted chiefly of residual chromatin derived from the nuclei of food organisms. Formerly this basophilic material was regarded as chromidia, which later gave rise to nuclei, or was mistaken for gametic nuclei by investigators whose cytological methods did not result in well-defined nuclei, especially during division stages. The failure of the chromatin of dividing nuclei to stain appreciably has been experienced by investigators in other groups of rhizopods, but where the nuclei are as clearly defined as those of the species under discussion no confusion should result. For the cytological investigation of thick- 
walled polythalamous species of Foraminifera we do not recommend any of the methods of fixation commonly employed by cytologists, nor do we know of methods that are suitable for the investigation of nuclear division in these species.

\section{ECOLOGY}

Multiple tests may be found during the warmer months of the year in almost any rock-bottomed tide pool (Heron-Allen, I915, p. 247) that supports a close growth of fine, closely branching coralline algae, in which the wash of the surf does not remove the last traces of sediment from around the hold-fasts. When searching for these organisms one should not neglect to examine small rock pools which are soon exposed by the receding tide, especially if the water is renewed occasionally by the splash of waves, for such a pool often supports a relatively dense population of smaller plant and animal organisms, including many species of Foraminifera, and will be accessible when pools at a lower level on the beach cannot be reached.

The distribution of species in which multiple tests occur is somewhat erratic and it may be necessary to explore several pools, or even beaches before material containing appreciable numbers of paired tests is found. An experienced collector will quickly learn to locate not only favourable pools, but areas within a pool in which one or more of these species are numerous. A teaspoonful of sediment washed from coralline algae may yield from a few to more than roo multiple tests.

In southern California, multiple tests were found from late in April until early November, or during that part of the year when the mean surface temperature in the sea is above $17^{\circ} \mathrm{C}$. In northern California these reproductive stages were not numerous until one month later. Where the coast is exposed to the open sea, most Foraminifera are washed from the tide pools into the deeper water during the periods of heavy surf which occur in the late fall. At this same time of year, tests of Foraminifera found in great numbers in ripple marks on sandy beaches are, for the most part, those of species which do not inhabit the intertidal zone. How far these organisms were transported is unknown. From these observations it is evident that the bathymetric range of the species of Discorbis studied cannot be based on the reported occurrence of empty tests found in marine sediments. The bathymetric range of these species is limited probably by the distribution of the algae upon which they occur. An investigation of this problem is being attempted at the Plymouth Laboratory by making a comparative study of species actually living on a bottom with those found in the sediments.

Most tide-pool species of Foraminifera are not easily washed from the wall of a culture dish by a stream of water forcefully driven from a pipette, and when we consider the protection afforded by the network of algae, tubes of annelids, cases of amphipods, and similar objects among which they live, we can understand how they persist in tide pools exposed to a pounding surf. 
These organisms move and feed by means of finely attenuated filaments of anastomosing ectoplasm, the pseudopodia. While the cytoplasmic inclusions of many Foraminifera reveal the nature of food organisms, the small diameter of the aperture in tests of $D$. patelliformis, $D$. ornatissima, and $D$. opercularis do not admit diatom frustules or similar objects. These species feed upon a substratum composed of plant and animal debris, supplemented by unicellular algae, and an occasional soft-bodied larval stage of a mollusc or other metazoan organism. Proteolitic ferments in the pseudopodia reduce the food to a fluid state so that it can be transported through the small aperture of the test or even through the pseudopodial pores into the endoplasm where liquid vacuoles are formed. Many of these vacuoles contain chromatin, derived from the nuclei of food organisms, which stains heavily with basic stain. The slow rate at which chromatin is metabolized results in the accumulation of this material in the cytoplasm.

The only organisms observed preying upon these smaller tide-pool Foraminifera were certain polychaete annelids. Many Foraminifera become the hosts of nematode worms, but the nature of the test of the species under consideration did not permit the entrance of either worms or eggs. Occasionally individuals were found in which one or more chambers of the test contained vast numbers of bacteria, amoebulae, or flagellates, not gametes; while other tests were partially or completely filled by the plasmodia of a Mycetozoa, and at this time the nucleus was usually abnormal.

Fertilization and the development of the microspheric generation takes place within the common space which forms between the several megalospheric tests comprising a group, as was also demonstrated in Patellina corrugata and Spirillina vivipara. Since the gametes of the species in which multiple tests occur are at no time free and pelagic, this stage in the life cycle does not constitute a factor in dispersal and distribution. It is evident therefore that dispersal must occur either in the juvenile or adult stages, largely as a result of turbulence and current action. A limited distribution of species may be accounted for by the migration of larger organisms especially arthropods in which the carapace is frequently covered with barnacles, bryozoans, hydroids, algae and other material providing a suitable habitat for many Foraminifera. Encrusted molluscs, especially the abalone, have been an abundant source of more than twenty species of Foraminifera, many of which were difficult to obtain in quantity from any other source. Transportation by sea weed, eel grass, or other floating objects may result in a more extended distribution and account for the dispersal of tests of Foraminifera found in sediments at depths at which these species do not occur, often hundreds of miles from a probable source. We have not observed multiple tests of Foraminifera occurring in deep water, and it is probable that here the gametes of most species are free, and constitute a brief pelagic stage during which, with the aid of such currents as exist, they would surely be a factor in dissemination, and in time distribution. 
Discorbis patelliformis found in tide pools of southern California are smaller by one-half, show only two convolutions of chambers, never three, and the superior surface is rough, not smooth, compared with tests described by Brady (I884), otherwise the original description of this species agrees closely with the material studied. Several species of Foraminifera from tide pools of the La Jolla region show a similar reduction in the total diameter of tests of adult organisms, compared with those described from dredgings from other regions. At Plymouth, England, tests of Elphidium crispum (Polystomella) collected in tide pools seldom show more than one-half the number of chambers observed in organisms of the same species dredged from adjacent channels, at a depth of about $5 \mathrm{~m}$. below mean low tide, during the months of July to December inclusive. It is probable that larger examples of the species taken from tide pools at La Jolla might occur in deeper water in the same region. Foraminifera maintained in cultures at $2 \mathrm{I}^{\circ} \mathrm{C}$. reproduced in an earlier growth stage than those recovered from tide pools where the temperature of the water was several degrees colder; the mean temperature in a tide pool is usually several degrees warmer than that of larger bodies of water. From these observations it would seem that the maximum growth attained by certain species of Foraminifera is limited directly, or indirectly, by the mean temperature of the water in which they occur. The distribution of larger geologic and recent species of Foraminifera has been limited to warm shallow seas, hence this statement only applies to organisms of the same species living under different environmental conditions.

\section{LIFE CYCLE}

The zygote which results from the union of two gametes in fertilization is considered the natural beginning for the description of the life cycle, but in the present instance the flagellated gamete is the stage of greatest interest; for proof of its existence has been the object of investigation for more than 40 years. It is for this reason that the present account begins with a description of the gamete.

Gametes. Gametes of $D$. patelliformis, removed from multiple tests and observed in life by transmitted light, at a magnification of 1000 $\times$ have an average length of $8 \mu$, and a slightly flattened, ellipsoidal shape, but are capable of much distortion owing to the fluidity of the protoplasm and the elastic nature of the delicate bounding membrane (Pl. II, fig. I6). Three long flagella have their origin at one side of the anterior end where a slight notch, suggestive of a cytopharynx, is occasionally observed. This false cytopharynx does not show clearly in stained preparations. At one side and somewhat posterior to this a large hyaline area, with no visible bounding membrane, marks the position of the nucleus. Conspicuous cytoplasmic inclusions, confined largely to the distal half of the gamete, consist of from a few to more than ten vacuoles, the contents of which are often coloured, one or more of the 
larger usually containing a golden yellow, oil-like substance, while others show irregular yellow-brown bodies having a high index of refraction.

Two of the three flagella are of the same length, and usually beat in unison. The stroke, beginning at one side, carries both flagella forward along the same course in a wide arc, and back to complete a whirling motion that is repeated at more or less regular intervals. The third, a trailing flagellum, originates a short distance posterior to the paired flagella, is somewhat longer, and waves slowly about at random. The amount of forward progress is negligible compared with the energy expended both in body contortions and flagellar activity. Occasionally a gamete becomes attached to the glass slide at the point of contact, or by a protoplasmic process pushed out from one side, and as the organism struggles as if to free itself, the cytoplasm is drawn out into a long hyaline filament: this false pseudopodium frequently includes the trailing flagellum. A gamete attached by the anterior end becomes subspherical in shape, and as it rotates slowly about the point of attachment the paired flagella thrash about more actively than the third, which waves slowly from side to side.

Under favourable conditions the gametes contained in multiple tests persist for about $24 \mathrm{hr}$. Certain multiple tests placed in isolation cultures still contained active gametes after 22-34 days, but there is no evidence that these gametes were capable of fertilization after the first day. This observation may or may not suggest the persistence of gametes in those species in which the gametes are free and pelagic, and no doubt constitute a factor in dissemination and distribution (Vaughan, I933).

If conditions in a culture become unfavourable, the gametes develop tumourlike processes containing large pigmented vacuoles, which are finally pinched off together with the surrounding cytoplasm. In the final stage of degeneration of the gametes the paired tests contain only a small amount of brownish granular residual material, largely composed of stercombs.

In a fresh preparation of gametes the three flagella are easily demonstrated by placing a drop of sea water strongly coloured with iodine near the edge of the cover-glass; and as the iodine solution spreads to the gametes, the flagella shorten, thicken, and stain deeply. Gametes exposed to osmic acid vapour, followed by hot Schaudinn's fluid, and stained with iron haemotoxylin resulted in satisfactory preparations, both for nuclei and flagella. Gametic nuclei usually stained intensely. When weakly stained, the nucleoplasm appears finely granular and is bounded by a delicate membrane. Each flagellum originates in a small basal body situated immediately below the periplast, those of the paired flagella being slightly anterior to that of the trailing flagellum. The latter is connected to the nucleus by a rhizoplast, but the relation of this structure, or of the nucleus to the paired flagella, was not determined. Certain vacuoles containing a lipoid substance blacken when treated with osmic acid; while the content of others stained darkly with haematoxylin, especially in organisms recently removed from the sea. These 
latter no doubt contain residual chromatin derived from organisms utilized as food by the megalospheric gamont. Brown bodies, probably stercombs, have a high index of refraction, and persist apparently unchanged in stained preparations.

The gametes of many plant and animal organisms are provided with either one or two flagella, three is a most unusual number. The flagellated organisms tentatively described as gametes or "zoospores" by Lister (I895, p. 427) were provided with two flagella. Gametes of Foraminifera having two flagella have since been described by several investigators, the one exception being the mono-flagellated gametes of Peneroplis pertusus Forskål (Winter, 1907). In the course of the investigation on the biology of the Foraminifera carried on for several years at the Scripps Institution of Oceanography of the University of California at La Jolla, California, flagellated gametes of Discorbis and Tretomphalus were available for demonstration much of the time, and were observed by many visitors. Brief comments on these observations have been made in earlier papers (Myers, 1933-38), but the unsatisfactory state of the cytological evidence as to the origin and fate of these flagellated organisms, at that time, justified a conservative view as to their significance in the life cycle of the Foraminifera.

The dimorphic nature of the tests, the number of nuclei in microspheric agamonts and megalospheric gamonts, and the morphology of both nuclei and tests in the species of Discorbis under discussion are in agreement with the characteristics prevailing in other polythalamous species of Foraminifera in which life cycles have been proposed. It is interesting that the gametes of these small species of Foraminifera should be nearly twice the size of those described by other investigators in relatively enormous species, and that the number of flagella should be three, and never one or two.

Soon after the first progamic nuclear division in gametogenesis, the ventral walls and septa of megalospheric tests of organisms associated in sexual reproduction are slowly dissolved, and the calcium carbonate so derived, assimilated by the protoplasm for redeposition during the secretion of the tests of the new generation (P1. II, figs. I2, 20). The passage thus formed between the tests permits the fusion of the several somatellae. Following multiple fission of the multinucleate megalospheric somatellae and the development of the gametes, the reproductive bodies are free to mingle within the enclosed space or brood chamber formed by the outer walls of the excavated multiple tests.

Each of the Foraminifera comprising a group of associated $D$. patelliformis produced from 250 to 300 gametes, of these only twenty to thirty were destined to become fertilized and develop into sexually produced young. From material killed and fixed immediately upon being removed from the sea, at least onethird of all multiple tests contained gametes. In cultures, approximately $72 \mathrm{hr}$. elapsed between the association of the Foraminifera in multiple tests and the final escape of the sexually produced juvenile microspheric agamonts. 
From the above it would seem that the gametes normally persist for a period of at least $24 \mathrm{hr}$. Since only about one gamete in eleven becomes fertilized under conditions that afford the maximum opportunity for syngamy, the probability of actually observing the union of two gametes in fertilization is relatively remote.

\section{Sexual Reproduction}

Fertilization. From the behaviour of the gametes, and the position of the flagella and nuclei in living and stained preparations, it appears that union begins near the anterior end; the two gametes finally assuming a parallel position so that when fusion is complete, the flagella are near one pole, and the two pronuclei are in line at right angles to the major axis of the somatella. The direct fusion of the two pronuclei completes fertilization.

Growth following fertilization results from the ingestion and assimilation of entire gametes as is evidenced by the content of large vacuoles, and the presence of ten to fourteen picnotic gametic nuclei in the cytoplasm of the primordium of the microspheric agamont (Pl. II, fig. 20). This interesting form of cannibalism is a normal activity, and is not the result of unnatural conditions in cultures, for the number of sexually produced microspheric juveniles both in cultures and in the sea is entirely dependent upon the size of the brood chamber; this was apparent in cytological preparations in which it was observed that the two-chambered juveniles completely fill the common space enclosed by the multiple tests in material obtained from both sources.

The flagella persist during early growth of the post-zygotic amoebula and slowly wave about, but seem to have slight influence upon the movements of the organisms. Vacuoles, nuclei of ingested gametes, and the zygotic nucleus churn about in the vortex set up in the cytoplasm.

Metagamic nuclear divisions. In stained preparations the chromatin of the zygotic nucleus remains optically unchanged while the expanding mass of hyaline nucleoplasm carries the nuclear membrane outward, resulting in a large spherical nucleus with a deeply staining central mass (P1. II, fig. I7 a). The gradual expansion of this central mass brings into view a tangled spireme which soon occupies the entire nucleus. An orderly series of post-zygotic or metagamic nuclear divisions quickly follow, without the intervention of interphase or resting nuclei, the linear aggregates of nuclear substance which marks the position of ill-defined chromosomes apparently retaining their organization from one division to the next (PI. II, fig. I $7 b$ ). It is interesting that the zygotic nucleus and the picnotic nuclei should have stained while dividing nuclei usually failed to stain appreciably except in the final metagamic nuclear division (Pl. II, fig. I5). Later, digestive ferments acting upon the nuclei of the ingested gametes caused them to swell and gradually lose their affinity for basic stains.

Cytological preparations showing metagamic nuclear divisions should have been made by first removing the developing microspheric juveniles from the 
multiple tests, thereby eliminating mechanical and chemical interference to the action of fixatives, although there is little to suggest that this would have resulted in a more favourable staining reaction with the reagents and stains used.

Motility in the gametes and later in the multinucleate post-zygotic stages is more dependent upon a modified type of amoeboid movement than upon flagellar activity, although the flagella persist until the developing agamont has attained a size equal to about two-thirds that of the protoplasmic mass contained within the proloculum, or initial chamber of the microspheric test. About this time the developing agamont becomes surrounded by a layer of hyaline ectoplasm, which gives rise to filose pseudopodia. Within this ectoplasm a thin transparent layer, or wall of calcium carbonate forms in close contact with the bounding membrane. This subspherical primordial test becomes the initial chamber, or proloculum of the test of the microspheric generation, and is perforated by a number of pseudopodial pores and a larger opening, the aperture. The calcium carbonate contained in the juvenile tests was largely derived from the ventral walls and septa of the associated megalospheric tests which were digested and assimilated during gametogenesis (Pl. II, fig. Io).

The diameter of this monolocular juvenile test which becomes the pro-loculum of the microspheric test is dependent not upon the size of the gametes, as is perhaps the case in species in which the gametes are free and pelagic, but upon the amount of growth taking place before the primordial test is formed. After the secretion of the primordial test, all nuclei may show from three to eight basophilic masses or endosomes pressed against, or in close contact with the nuclear membrane and resemble the vegetative nuclei of other Foraminifera (P1. II, fig. I7 c). The remaining nucleoplasm at this time is often lacking in visible structure and staining capacity, and the nuclear membrane is indistinct, so that when the cytoplasm contains small masses of residual chromatin or other inclusions, the organization of the vegetative foraminiferal nucleus with its multiple endosomes must be known before these nuclei can be recognized; once observed, they show clearly in all organisms within a multiple test. Later, a mass of ectoplasm escapes through the aperture and assumes a subspherical shape in contact with one side of the primordial test. After the secretion of a delicate chitinous membrane, protected externally by a thin wall of calcium carbonate, the more granular endoplasm streams through the aperture, which is now a foramen, into the newly formed chamber. In cytological preparations the gametic nuclei, and the zygotic nucleus resulting from the union of two gametic nuclei in fertilization, stain so that their organization is clearly defined. Later, an orderly progression in numbers of nuclei can be observed which, as a rule, do not stain appreciably, but which do show linear aggregates of nuclear substance indicative of chromosomes. The first vegetative nuclei in the multinucleate microspheric juvenile before it escapes from the multiple tests stain clearly, 
and are characteristic of the species (Pl. I, fig. 5; Pl. II, fig. I7 c). Thus the fate of the triflagellate gametes has been demonstrated on cytological evidence, and further it was observed that the post-zygotic nuclei divide by mitosis.

When multiple tests containing gametes are viewed with the aid of a microscope and oblique illumination it is possible to see the twisting, gliding movements of the gametes through the translucent walls as they mingle in the common space formed by the dissolution of the ventral walls and septa of the several tests. Later, the larger slow-moving post-zygotic amoebulae can be noted, but after the secretion of the primordial tests movement is too slow to be distinguishable. The gametes, together with the earlier developmental stages of the zygotes, persist for about $24 \mathrm{hr}$. $24 \mathrm{hr}$. later the animal cement and calcium carbonate, which securely bound the megalospheric tests, is dissolved by the pseudopodia of the juveniles, and the two- and three-chambered microspheric young glide slowly from between the tests to the substratum where they are soon dispersed; by the next morning only a few of the juveniles are to be found in the vicinity of the now empty and separated tests from which they escaped. The usual number of sexually produced microspheric juveniles derived from a pair of associated megalospheric gamonts varies from eighteen to thirty-two, although larger and smaller numbers of young have been observed.

Development of microspheric test. At the time of escape, each microspheric juvenile contains eight to sixteen nuclei. After each period of active foraging a new chamber is added to the juvenile test. These chambers, which are formed one at a time, result in a graduated series in which each additional chamber is larger than the one preceding. In an occasional test, the regularity of the series is interrupted by the addition of an unusually narrow chamber. In cultures an abrupt change in temperature or food organisms in the substratum has been known to result in a similar reduction in the size of chambers in numbers of individuals. In the microspheric generation, the direction of rotation of the series of chambers is to the right, or clockwise. In Discorbis patelliformis an exception to this rule is most unusual. In megalospheric tests no exceptions were found in which the direction of rotation was not the reverse of that observed in microspheric tests (Pl. I, figs. I, 2). This statement is based on observations of permanent preparations of tests of three hundred organisms associated in sexual reproduction which were separated and cleared in balsam before measurements and chamber counts were made. A similar study of microspheric tests was also made from preparations of organisms removed from cultures during asexual reproduction, or while the juvenile Foraminifera were still in close association with the parent test. A reversal in the direction of rotation of microspheric and megalospheric tests was reported in Spirillina vivipara (Myers, 1936). Føyn (1936b), in the same year, described a similar condition in Discorbis vilardeboana d'Orbigny where exceptions to the rule were not uncommon. In megalospheric tests of Tretomphalus bulliodes d'Orbigny, exceptions were even more numerous (Myers, in manuscript). 
Table I shows the relative size of the proloculum or initial chamber of microspheric to megalospheric tests in four species of Foraminifera. In the first two species listed, the gametes are confined within a brood chamber; in the remaining species, the gametes are free and pelagic.

TABLE I

\begin{tabular}{|c|c|c|c|c|c|c|}
\hline & $\mathrm{Mic}$ & pheric & & Meg & spheric & \\
\hline & Proloct & & & Proloct & & \\
\hline Species & Extremes & Means & $\begin{array}{l}\text { tests } \\
\text { test }\end{array}$ & Extremes & Means & $\begin{array}{l}\text { No. on } \\
\text { tests }\end{array}$ \\
\hline D. patelliformis & I $5 \cdot 3-2 \mathrm{I} \cdot 3 \mu$ & I $7 \cdot \circ \mu$ & I00 & I $5.3-28.9 \mu$ & $\mathrm{I} 7.8 \mu$ & 300 \\
\hline D. opercularis & I $5.0-24 \cdot 2 \mu$ & $20.3 \mu$ & 100 & $18.2-29 \cdot 3 \mu$ & $22 \cdot 3 \mu$ & IOO \\
\hline D. concinmus $\star$ & $6.4-9 . \mathrm{I} \mu$ & $9 \cdot 4 \mu$ & $4 \mathrm{I}$ & I3.6-22.I $\mu$ & I $5.2 \mu$ & 300 \\
\hline crispa & $6.3-13.4 \mu$ & $9 \cdot 2 \mu$ & $3 I$ & $5 \mathrm{I} \cdot 0-87 \cdot 4 \mu$ & $64.7 \mu$ & 300 \\
\hline
\end{tabular}

* Microspheric stage of Tretomphalus bulloides has been identified as Discorbis concinnus Brady by Arthur Earland.

Table II shows the growth stage at the time of reproduction, both in the sexual and asexual phases of the life cycle, based on the number of chambers in a test.

TABLE II
Chambers at time of reproduction

The addition of a new chamber to a foraminiferan is the result of a discontinuous method of growth only, and the nucleus, or nuclei, do not divide when a new chamber is added to the test. Therefore the addition of a chamber should not be considered an abortive attempt on the part of a foraminiferan to reproduce by budding, any more than the addition of a new chamber to the shell of a Nautilus suggests binary fission in this cephalopod mollusc.

The outer wall of the test of Discorbis patelliformis consists of laminated layers of calcium carbonate, separated by a mere trace of animal matter deposited on a basic chitinous membrane of insufficient strength to show the characteristics of the species after decalcification, unless the chitinous structures are supported by the protoplasmic body or somatella. In many species of Discorbis the chitinous portion of the test is brown in colour, has considerable substance, and shows characteristics similar to those of the entire test. Growth in $D$. patelliformis is accomplished by the addition of chambers and, during the interval when a new chamber is being added, protection is necessary because any slight injury to the developing chamber at this time would result in a malformed chamber, and with the addition of subsequent chambers, an irregular test. 
Addition of a new chamber to a test. When a foraminiferan of this species is about to add a new chamber it comes to rest on a flattened surface from which it removes any bits of debris that may be present. Long filose pseudopodia collect residual plant and animal matter, including many diatom frustules as well as small mineral crystals, from the substratum and these are heaped about the base of the test. This mass of debris is held together with animal cement and is lined by a smooth membrane secreted by the ectoplasm, which also covers the organism and is sealed at the margin of the test to the substratum. After the development of the growth cyst, the foraminiferan moves to one side, or is forced back from the wall of the cyst by a mass of clear colourless cytoplasm which escapes through the ventral aperture and gradually assumes the shape and size of the developing chamber. Bright points on the surface of the protoplasmic mass show where crystals of calcium carbonate are forming and these fuse to become a continuous layer of shell substance covering not only the new chamber but several of the adjacent chambers as well. The former aperture is now a canal or foramen between the new and preceding chamber, and a new aperture develops in the new or terminal chamber. In $D$. patelliformis we could not determine how the pseudopodial pores were formed; but in Tretomphalus bulloides, especially in the final chamber of the megalospheric test, the pores were observed to result from the deposition of shell material around the base of short pseudopodia extending through the chitinous covering of the developing chamber to the wall of the cyst, and were not formed after the shell substance had once been deposited. About I $2 \mathrm{hr}$. are required for the completion of one of the larger chambers of the test, from the time when the growth cyst can first be detected; while in the two- and three-chambered juveniles, two chambers may be added within the first $24 \mathrm{hr}$., allowing a period of $\mathrm{I} 2 \mathrm{hr}$. or more for active foraging between the deposition of the two chambers. After the escape of the foraminiferan from the growth cyst, the amount of cyst material remaining on the wall of the culture dish may be negligible, but if considerable loose material is available, a small hollow mound of debris may persist for several days.

Nuclei of microspheric agamonts. During early growth the nuclei of a microspheric agamont remain in the initial chamber or proloculum. Later, as new chambers are added, the nuclei become distributed farther along the series and increase in size according to the size of the chamber in which they occur, although nearly one-half the total number usually remain within the proloculum until the organism approaches maturity. Nuclei rarely occur in chambers less than two removed from the terminal chamber in organisms that are more than one-third grown. The total number of nuclei varies from eighteen to twenty-five, and in size from 3 to Io $\mu$ (Pl. I, fig. 6). During the vegetative life of the microspheric agamont, large nuclei show numerous masses of basophilic material, or multiple endosomes, in close contact with the nuclear membrane. These endosomes develop from small granules and several may coalesce to form larger endosomes; but they do not seem to divide 
at this stage, nor do the nuclei divide so long as these endosomes retain their affinity for basic stain, nuclear division being limited at this time to the smaller nuclei within the proloculum or adjacent chambers. There is no evidence that the division of these small nuclei coincides with the addition of a new chamber, while in the megalospheric gamont the nucleus does not divide until gametogenesis (P1. II, fig. II). In Discorbis patelliformis microspheric agamonts observed in asexual reproduction usually show from sixteen to eighteen chambers, the extremes being twelve and twenty-four chambers: the age of these agamonts averaged about 42 days. When conditions were less favourable the microspheric agamonts continued to grow, or remained relatively inactive for more than twice that period before undergoing asexual reproduction.

\section{ASEXUAL Reproduction}

Division of nuclei. Asexual reproduction in a microspheric agamont is initiated by the development of a multiple fission cyst, which is formed of diatom frustules and other debris in much the same manner as that described as the growth cyst, except that it is more rigidly constructed. No appreciable part of the debris in this structure consists of defecatory material eliminated by the foraminifer in the reorganization of the cytoplasm as was observed by Føyn (1937, p. 5) in D. vilardeboana. This statement is based on the observation that in D. patelliformis and related species rigid cytoplasmic inclusions show fragments of diatoms, but entire frustules or other large objects were not observed. After encystment all nuclei move farther along the series of chambers, the smaller nuclei increasing in size and developing numerous small dense bodies which are evenly distributed below, and in contact with the nuclear membrane, and which stain weakly. In larger nuclei, the intensely staining multiple endosomes become reduced in size, and stain less intensely with basic stains. Only the larger nuclei divide, and from the size and total number of nuclei after the final division it is evident that only the largest nuclei divide a second time.

In $D$. opercularis all nuclei in the somatella of a microspheric agamont may divide at least once. In this species the number of megalospheric juveniles asexually produced is from ninety to one-hundred and twenty, or about three times that observed in $D$. patelliformis; however, the final number of nuclei in microspheric organisms of both species prior to asexual reproduction is rarely in excess of twice that occurring in free microspheric agamonts having a similar diameter.

Multiple fission. In D. patelliformis multiple fission is preceded by a reorganization of the cytoplasm in the vicinity of each nucleus, where it becomes more homogeneous in appearance than the surrounding cytoplasm; which in stained preparations appears coarsely vacuolated. The nuclei at this time do not differ appreciably, either in size or staining capacity; and the inner side of the nuclear membrane bears numerous small masses of nuclear sub- 
stance or endosomes which are uniform in size and distribution, but stain poorly (Pl. I, fig. 7). The cytoplasm and contained nuclei recede from the earlier formed chambers, while the septa and much of the test substance, especially in the ventral wall, is digested and assimilated in the same manner, and for a similar purpose as that described in multiple tests in the sexual phase of the life cycle. Multiple fission results in the separation of the cytoplasm bounding each nucleus from the surrounding cytoplasm, each mononucleate mass approximating in size to the protoplasmic mass contained in the proloculum of the megalospheric test. These mononucleate somatellae become surrounded by a plasma membrane and later by hyaline ectoplasm which gives rise to filose pseudopodia. When multiple fission is complete, small angular anucleate masses of cytoplasm remain which are later utilized as food by the developing mononucleate megalospheric gamonts.

Development of the gamont. The mononucleate amoebulae move about within the excavated microspheric test and continue to digest the calcium carbonate in the walls and septa as well as the residual cytoplasm that remained after multiple fission. Following the development of the monolocular test, or megalosphere, the multiple endosomes in the nucleus stain intensely. A second chamber is added in much the same manner as that described in the development of the tests of the microspheric generation (PI. I, fig. 8). It is difficult to explain why in certain stained preparations the more granular endoplasm lines this first chamber, while a more hyaline cytoplasm forms a distinct central mass, unless it represents a stage prior to the secretion of the third chamber (Pl. I, fig. 4). It is evident that the shell substance is deposited by the ectoplasm in all cases. About $70 \mathrm{hr}$. after the first bits of substrate debris becomes noticeable in the developing multiple fission cyst, the ventral wall of the test of the microspheric agamont breaks down, and from thirty to forty, two- and three-chambered megalospheric gamonts glide slowly from the parent test and collect in a closely associated group, not unlike a brood of chicks about a mother hen.

The nucleus of the megalospheric gamont may remain in the proloculum or initial chamber as long as the organism is free, or it may move along the series of chambers, but rarely beyond the chamber that is numerically near the middle of the series (Pl. II, fig. II). The nucleus increases in size with the growth of the organism and may exceed in magnitude the largest nucleus observed in microspheric agamonts (P1. II, fig. I3). Nuclei of megalospheric organisms have an average diameter of $10 \mu$; while the largest nuclei in microspheric agamonts seldom exceed $8 \mu$. These large nuclei are similar in appearance in both generations. In order to determine the rate at which these Foraminifera develop in cultures, culture dishes which had been previously inoculated with material from the substrate of a culture was allowed to develop a similar substrate. These dishes were then planted with as many day old Foraminifera as were available. By observing the average rate at which new chambers were added to the primordial test, it was possible to determine 
the rate of growth and the age at which these organisms reproduce. As might be expected, in organisms in which the initial stage of both the sexual and asexual generation is about equal in size, a greater difference was observed in the rate of development of individual organisms of the same age than between organisms of the two generations, although a slightly accelerated rate of growth was noted in the multinucleate microspheric agamonts : this apparent variation in the rate of growth being influenced perhaps by the number of nuclei occurring in organisms in the respective generations. The metabolic rate of a Foraminifera is influenced perhaps by the surface area of contained nuclei.

The total number of chambers in tests of megalospheric gamonts associated in sexual groups varies from six to sixteen, the largest test showing fewer chambers than was observed in the majority of tests of microspheric agamonts after asexual reproduction. Multiple tests in $D$. patelliformis usually include one or more organisms showing ten, eleven, or twelve chambers, which in cultures require about I6 days to develop. These Foraminifera had not attained the maximum size for the sexual phase of the life cycle and might have continued to grow as free organisms for weeks or even months under other conditions.

The final chamber in a mature microspheric agamont is usually smaller than the several which preceded it and occupies the angular space formed by the preceding chamber and the final whorl of chambers so that the inferior surface of the test is nearly level. In megalospheric tests the distal face of the final chamber terminates more abruptly, so that an angular space remains between the inferior surface of the test and the substrate.

Syzygy. Foraminifera of different species, or of the same species, usually avoid one another in cultures. When two megalospheric organisms, each provided with a test consisting of ten or more chambers, were observed in close contact on the wall of a culture dish, the position was marked on the outside of the dish by a numbered wedge-shaped piece of gummed paper. Many groups so marked could be observed at frequent intervals. The slow rate at which these organisms move made it necessary to trace these movements in series of drawings.

From the behaviour of two Foraminifera immediately prior to their association in syzygy in the sexual phase of the life cycle, it would seem that a conditioning process is necessary in one or both individuals, for two megalospheric gamonts rarely approach and fuse directly. While one megalospheric gamont remains quiescent, the other, which is frequently the smaller, shows unusual activity, and makes many attempts to move under the test of the larger at the point where it fails to make contact with the substratum. The inferior surface of the two tests thus brought into juxtaposition may separate and the smaller organism resume its random movements over and around the larger, the two organisms at times being separated by a distance equal to as much as ten times the diameter of the larger test. After effecting one or more tem- 
porary unions, the two gamonts finally come together, the one rotating on the other, so that the distal or apertural face of the final chamber of each test is opposed and the ventral surfaces are in close contact at all points (Pl. II, fig. 9). Both organisms are provided with long filose pseudopodia, which extend in all directions. The lower organism of a pair rests on one side of the conical superior surface, and while in this position the paired tests glide over the surface of the dish a distance equal to ten or more times the diameter of the multiple tests. The multiple tests soon become firmly attached to the substratum by a deposit of animal cement. Animal cement and calcium carbonate also seal the two tests together so that no opening larger than a pseudopodial pore communicates with the outside. So firmly are the tests fused that if an attempt is made to separate them, the inferior surface of one is frequently broken away. The described activities require from I to more than $5 \mathrm{hr}$. One multiple test transferred to a depression slide moved about for $4 \mathrm{hr}$. before becoming attached. Union is not always effected in a symmetrical manner and it is not essential that the apertures of the several tests be opposed. When a multiple test consists of three or four gamonts, they may assume almost any position that will allow the ventral surface of each to make contact with at least one other test; thus permitting the development of a wide passage between the several tests by the dissolution of the walls at the point of contact. Since one of a pair of Foraminifera associated in sexual reproduction may consist of five chambers or less, Heron-Allen (I915) had reason to presume that multiple tests were the result of budding. It was observed that the gamonts associated in syzygy may or may not have been asexually derived from the same microspheric agamont. The variation in the size of gamonts in multiple tests further supports this observation.

Gametogenesis. The association of megalospheric gamonts is probably a response to a chemical activator. These gamonts are further activated so that subsequent events in the several organisms are nearly synchronous. After the union of the gamonts in syzygy there is a gradual dissolution of the septa and ventral walls of the respective tests so that the cytoplasm in the later formed chambers becomes confluent in the umbilical region and the somatellae fuse in the passage formed between the several tests. As is characteristic of the nuclei of all polythalamous Foraminifera studied, the large basophilic masses of nuclear substance, or multiple endosomes, lose their affinity for basic stains and become greatly reduced in size or disappear entirely prior to nuclear division (PI. II, fig. I5). The first progamic nuclear division in which the large single nucleus of each gamont divides takes place about $24 \mathrm{hr}$. after the association of the gamonts. There immediately follows an orderly series of progamic nuclear divisions without the intervention of interphase or resting nuclei. These divisions result in a gradual reduction in the size of the nuclei, although this reduction in size is not in proportion to the number of nuclei produced (Pl. II, figs. I2, I4 and I8).

The nuclei of one gamont are usually larger, and fewer in number, than 
those of the other gamont as a result of one less nuclear division. During this series of progamic nuclear divisions the nuclei become equally spaced in the cytoplasm. A slight difference in the appearance of the nuclei of the respective gamonts makes it possible to determine that no exchange of nuclei occurs during gametogenesis. Indistinct linear aggregates of nuclear substance in nuclei which are spherical, elliptical, or constricted in the middle are indicative of mitotic division, as is the orderly increase in numbers of clearly defined nuclei. In a later paper on the Cytology of the Foraminifera we hope to be able to demonstrate conclusively the nature of the chromatic and achromatic elements of the division figures in larger nuclei of this and other polythalamous Foraminifera.

Multiple fission in the multinucleate somatella, as evidenced in cytological preparations, show open spaces between oblong masses of cytoplasm which are provided with a centrally situated nucleus. Nuclear division and plasmotomy take place in rapid succession, the spindle-shaped nuclei showing chromosomes which stain (P1. II, fig. I9). Since the basic plan of this life cycle closely parallels that of Patellina and Spirillina it would seem that these mononucleate oblong bodies are diploid gametocytes and that the spindle-shaped nuclei are indicative of the anaphase of the meiotic or reduction division. This final nuclear division and the binary fission of the gametocytes results in numerous small spherical bodies each having an eccentrically situated nucleus; these develop into the triflagellate gametes.

\section{Comparative Study of Life Cycles of Foraminifera}

In the life cycle of $D$. patelliformis multiple tests result from the union of two mononucleate megalospheric gamonts associated in syzygy. About $24 \mathrm{hr}$. are required for the reorganization of the cytoplasm and the contained nuclei. Gametogenesis and fertilization occupy another $24 \mathrm{hr}$. period; while a third period of $24 \mathrm{hr}$. is necessary for the development of the two-chambered multinucleate microspheric agamonts, making a total of about 3 days that are required for sexual reproduction. The test of the microspheric agamont at the time of asexual reproduction shows an average of about seventeen chambers, indicating an age of at least 45 days. The asexually produced mononucleate megalospheric gamonts in multiple tests average about eleven chambers, and were not less than I4 days old at the time. $60 \mathrm{hr}$. or more elapse from the time the multiple fission cyst can first be detected until the juvenile megalospheric gamonts make their escape: therefore the minimum period required to complete the life cycle in cultures is in excess of 64 days.

The life cycle of many species of Foraminifera includes an orderly succession of sexual and asexual generations. This alternation of generations results in test dimorphism. The multinucleate microspheric agamont asexually produces mononucleate megalospheric gamonts, which in turn give rise to gametes. The union of two gametes in fertilization results in the formation of a zygote 
which develops into a microspheric agamont, thus completing the life cycle. This brief statement of the succession of stages applies equally to the life cycle of Polystomella crispa Lister (1895), Patellina corrugata (Myers, I935), Spirillina vivipara (Myers, I936), and the present account of the life cycle of Discorbis patelliformis. These four life cycles constitute an interesting series in which modifications of morphology and behaviour have no effect upon the basic plan of the life cycle.

In Spirillina vivipara the tests of both mononucleate gamonts, and multinucleate agamonts, consist of a proloculum that is continuous with a spiral chamber, the only obvious difference in the tests of the two generations being the larger diameter of that of the agamont. In asexual reproduction, the cytoplasm and contained nuclei escapes from the test of the agamont, and multiple fission and the development of the juvenile mononucleate gamonts follows. In sexual reproduction the gamonts associate in groups of two or more while in a horizontal position, and are enclosed within a protective cyst. Gametogenesis results in amoeboid gametes, not flagellated, which unite in pairs in fertilization, the zygotes so produced developing into juvenile agamonts. All nuclei in this life cycle are the result of mitotic division, the final division in gametogenesis being the reduction division.

The sequence of events in the life cycle of Patellina corrugata parallels closely that of Spirillina vivipara. The tests of the mononucleate gamonts like those of Spirillina seldom consist of more than a proloculum and a spiral chamber, while that of the multinucleate agamont shows, in addition to the proloculum and spiral chamber, five or six semi-lunar chambers, and is considerably larger.

In Discorbis patelliformis the tests of both generations consist of many chambers, that of the agamont being the larger as was true in both of the preceding species. Again the prolocula of the tests of both generations are about equal in size. In this species the mononucleate gamonts associate in such a manner that the inferior surfaces of the tests are opposed, and never assume a horizontal position during sexual reproduction. In this life cycle, as in those of the preceding genera, there are three periods of nuclear division, but in Discorbis post-zygotic divisions continue during the vegetative life of the agamont.

In Polystomella crispa agamonts do not associate prior to gametogenesis, the flagellated gametes being free and pelagic so that the zygote which results from the union of two gametes in fertilization do not have an opportunity to feed and grow at the expense of unsuccessful gametes. For this reason the proloculum of the test of the sexually produced agamont is small compared with that of the test of the asexually produced gamont, and the probability of survival is greatly reduced. Tests of both generations are provided with many chambers and are about equal in size. The sequence of events in the life cycle of this species, including the periods of nuclear division, closely parallels that of Discorbis patelliformis. 
The stratigraphic distribution and morphology of the tests of Spirillina attest to the antiquity of this genus, compared with Patellina, Discorbis and Polystomella. It has been presumed that flagellated gametes recapitulate the progenitor of all animal organisms. If it were not for this popular concept, one might propose that the increasing complexity of the tests of these genera and the modifications of events and stages in the life cycles are suggestive of an evolutionary series.

\section{CONCLUSIONS}

In the account of the life cycle of Spirillina vivipara it was stated "if flagellated gametes, or zoospores, do exist in the Foraminifera their origin and fate can and will be demonstrated cytologically" (Myers, 1936, p. 139). The present paper meets both of the requirements specified above. Much of the evidence herein presented, including many cytological preparations of critical stages and recorded observations, had been made during the four seasons preceding the publication of this statement (Myers, I933). Calvez, 1938, p. 173) has criticized Dr C. A. Kofoid and myself for assuming the attitude that organisms, flagellated or otherwise, observed in tests of Foraminifera were in all probability saprophytes, parasites, or symbionts until their genetic relation had been proven cytologically. Calvez has described flagellates, presumably gametes, in twelve species of Foraminifera. According to his descriptions the gametes of these twelve species are small and bear two flagella, one longer than the other. These characteristics are common to many flagellates, especially saprophytic species which enter the tests of dead, or dying Foraminifera, particularly in cultures, and also resemble certain flagellates observed by Lister (I895, p. 427) which he recognized as "products of some other organism which had entered the shell of Polystomella".

We have studied the origin and fate of flagellated gametes in several genera of Foraminifera in cultures and from permanent cytological preparations. It is significant that the flagellated gametes observed by us bear slight resemblance to those described by Calvez, even in the same species. This evidence will be described and figured in papers now in preparation.

The investigation of the biology of the Foraminifera gives promise of becoming an active field, due largely to the use of the tests of these marine rhizopods as guides in stratigraphic geology. The geographical distribution of many genera and species extends throughout the more populous sea-coast regions of the world, therefore we may expect that observations may be repeated. In so ancient and diverse a group, variations and modifications in stages and cytological behaviour are to be expected, and much caution is necessary in the interpretation of cytological preparations owing to the difficult nature of the material and the many types of organisms which inhabit the tests of both living and dead Foraminifera. 


\section{ACKNOWLEDGEMENTS}

The classic contributions of J. J. Lister on the life history of the Foraminifera were largely the result of observations made at the laboratory of the Marine Biological Association at Plymouth. It has been the privilege of myself and my wife Ethel, who assists me, to extend these observations in this and other species while working at the Plymouth laboratory. We wish to express our appreciation and gratitude to the Director, Dr Stanley Kemp, and the members of the staff who have co-operated to make our stay in Plymouth both instructive and pleasant. We are especially grateful to Dr E. J. Allen for his interest in the cytological preparations and other phases of the work and for his helpful suggestions. Multiple tests in Discorbis ornatissima were first called to my attention in 1934 by Helen Jean Plummer. Later we obtained multiple tests of this species in considerable numbers near Moss Beach, California. The photograph of multiple tests and contained young in Pl. III are of a preparation made by Dorothy Palmer which Miss Plummer kindly forwarded to me.

\section{SUMMARY}

It has long been presumed that the gametes of certain Foraminifera are flagellated; however, the lack of conclusive evidence as to the origin and fate of these flagellated gametes has made their existence problematical.

In syzygous species of Discorbis the gametes are flagellated and the genetic relationship of these gametes is easily demonstrated, since gametogenesis, fertilization, and the development of two- and three-chambered multinucleate microspheric agamonts takes place within the excavated tests of two or more mononucleate megalospheric gamonts associated in syzygy.

The life cycle of Discorbis herein described is in general agreement with the life cycle of Polystomella crispa proposed by J. J. Lister, and completes an interesting series of life cycles in which a progressive modification in behaviour and test morphology can be traced.

Behaviour, ecology, and distribution of four syzygous species of Discorbis are discussed.

Multiple tests of these syzygous species of Foraminifera can be found in most rock-bottomed tide pools that supports a growth of coralline algae. These sexual groups provide a sure source of material for the demonstration of flagellated gametes in the Foraminifera.

\section{REFERENCES}

BRADY, H. B., I884. Report on the Foraminifera dredged by H.M.S. Challenger during the years I873-6. Challenger Reports, Vol. IX, Zoology.

Calvez, J. LE, I938. Recherches sur les Foraminifères, Protistologica, LXXXvi. Arch. Zool. Exper. Gén., Tome 80, pp. I63-333, Pls. II à VII. 
FøyN, BJORN, I936 $a$. Über die Kernverhältnisse der Foraminifere Myxotheca arenilega Schaudinn. Arch. f. Protisten. Bd. 87, Heft 2.

- $1936 b$. Foraminiferenstudien. I. Der Lebenszyklus von Discorbina vilardeboana d'Orbigny. Bergens Mus. Arb. 1936, Natur. rekke Nr. 2.

- 1937. Foraminiferenstudien. II. Zur Kenntnis der asexuellen Fortpflanzung und der Entwicklung der Gamonten von Discorbina vilardeboana. Bergens Mus. Arb. 1937, Natur. rekke Nr. 5.

Heron-AlleN, E., I9I5. Contributions to the study of bionomics and reproductive processes in the Foraminifera. Phil. Trans. Roy. Soc., B, Vol. 206, pp. 227-79.

Lister, J. J., I895. Contributions to the life history of the Foraminifera. Phil. Trans. Roy. Soc., B. Vol. I86, pp. 40I-53, Pls. 6-9.

- I903. Foraminifera, in E. Ray Lankester, A Treatise on Zoology, pt I, 2nd fasc., pp. 47-I49.

Myers, E. H., I933. Multiple tests in the Foraminifera. Proc. Nat. Acad. Sci., Vol. 19, No. IO, pp. 893-9.

- I I935. The life history of Patellina corrugata Williamson, a foraminifer. Bull Scripps Inst. Ocean. La folla, Tech. Ser. 3, No. I5.

- I936. The life cycle of Spirillina vivipara Ehrenberg, with notes on morphogenesis, systematics and distribution in the Foraminifera. Four. Roy. Micr. Soc. Vol. 56, pp. 120-46.

- I937. Culture methods for marine Foraminifera of the littoral zone, in Culture Methods for Invertebrate Animals, Galtsoff, Paul, et al. Comstock Publishing Company, Ithaca, New York.

_ 1938. The present state of our knowledge concerning the life cycle of the Foraminifera. Proc. Nat. Acad. Sci., vol. 24, No. I, pp. IO-I7.

Rhumbler, L., I9I3. Die Foraminiferen (Thalmaporen) der Plankton Expedition. Erg. Plankton Exp. Humboldt Stiftung, 3, 1.c. Kiel und Leipzig.

Schaudinn, F., I895. Über Plastogamie bei Foraminifera. Sitz. Berichte ges. naturf. Freunde, Bd. I0, p. I70, Berlin.

- 1903. Untersuchungen über die Fortpflanzung einiger Rhizopoden. Arb. a. d. Kais. Gesundheitsamte, Bd. I9, Heft 3, pp. 547-76.

VAUGHAN, T. WAYLAND, I933. The biogeographic relations of the orbitoid Foraminifera. Proc. Nat. Acad. Sci., Vol. 19, No. 10, pp. 893-938.

WINTER, F. W., I907. Zur Kenntniss der Thalmaporen. I. Untersuchungen über Peneroplis pertusus. Arch. f. Protisten. Bd. Io, p. 83.

WRIGHT, T. STRETHILl, I86I. On the reproductive elements of the Rhizopoda. Ann. Mag. Nat. Hist., Ser. 3, Vol. vir, p. 360.

\section{EXPLANATION OF PLATES I-III}

Figures of Discorbis patelliformis in Pls. I and II are based on camera lucida drawings. The technique used was to select the foraminiferan from the culture with the aid of a dissecting binocular, the reproductive stages being recognized either from a protective cyst or as syzygous groups. The fixative used was hot Schaudinn's fluid. Total mounts were stained in Ehrlich's acid haematoxylin, and the paraffin sections in Heidenhein's iron haematoxylin.

\section{Plate I}

Fig. I. Discorbis patelliformis; superior surface of the test of a microspheric agamont.

Fig. 2. Superior surface of a megalospheric gamont. The direction of rotation of microspheric tests is dextral, megalospheric sinistral.

Fig. 3. Inferior surface of the test of a microspheric agamont.

Fig. 4. Cross-section of a two-chambered mononucleate megalospheric gamont.

Fig. 5. Cross-section of a two-chambered multinucleate microspheric agamont. 
Fig. 6. Decalcified total mount of a seventeen-chambered microspheric agamont showing twenty-five nuclei.

Fig. 7. Transverse section of a microspheric agamont showing the distribution and appearance of the nuclei prior to multiple fission.

Fig. 8. Transverse section of microspheric agamont test and cyst containing two-chambered mononucleate megalospheric gamonts.

\section{Plate II}

Fig. 9. Multiple test consisting of two megalospheric gamonts associated in syzygy.

Fig. Io. One of a pair of excavated megalospheric tests following the escape of the sexually produced microspheric agamonts.

Fig. II. Decalcified total mount of thirteen-chambered mononucleate megalospheric gamont.

Fig. 12. Cross-section of two megalospheric gamonts associated in syzygy, the gamonts showing one and two nuclei respectively.

Fig. I3. $a$, Nucleus of vegetative megalospheric gamont with multiple endosomes; $b$, early prophase nucleus showing the characteristic reduction in size and staining capacity of the multiple endosomes compared with those of the vegetative nucleus shown in Fig. I3 $a$.

Fig. I4. Cross-section of associated megalospheric gamont. One gamont contained four nuclei, the other eight, which suggests that two and three nuclear divisions had occurred in the respective organisms.

Fig. I5. Division figures of the final post-zygotic series prior to the development of typical vegetative nuclei.

Fig. I6. Triflagellated gametes of Discorbis patelliformis after fixation with osmic acid vapour followed with hot Schaudinn's fluid, and stained with iron haematoxylin. The gamete on the right bears a false pseudopodia in addition to three flagella.

Fig. I7. $a$, Zygotic nucleus during early growth; $b$, prophase of the first metagamic nuclear division; $c$, one of the vegetative nuclei of a juvenile microspheric agamont; the large multiple endosomes may or may not develop until after the escape of the megalospheric agamonts from the multiple tests.

Fig. 18. Partially excavated multiple tests showing the two multinucleate somatellae fused at the point where the inferior walls of the two tests have been dissolved.

Fig. I9. Two gametocytes showing anaphase nuclei of what is probably the reduction division. Three nuclei in the somatella of the second gamont. Multiple fission to form mono-nucleate gametocytes is usually delayed in the larger of a pair of gamonts associated in syzygy.

Fig. 20. Post-zygotic amoebulae within the brood chamber formed by the outer walls of the excavated multiple tests. Each amoebula contains, in addition to the zygotic nucleus, many picnotic nuclei of ingested gametes.

\section{Plate III}

Discorbis opercularis; Photomicrographs of cytological preparations. The Foraminifera were killed and fixed in hot Schaudinn's fluid, sectioned in paraffin, and stained in iron haematoxylin.

Fig. 2I. Multinucleate microspheric agamont. Section passes through the lower portion of the proloculum and the upper whorl of chambers.

Fig. 22. Multiple fission in a microspheric agamont. Section shows a portion of the content of three chambers.

Fig. 23. Earliest free stage of mononucleate megalospheric gamonts.

Fig. 24. Section through the major axis of a mature mononucleate megalospheric gamont.

Fig. 25. Median section through two gamonts associated in syzygy showing gametes within the brood chamber formed by the excavated megalospheric tests. Inset. Free gamete showing a trailing flagellum and the two tractile flagella as they would appear at midstroke (untouched).

Fig. 26. Monolocular, multinucleate microspheric agamonts within a multiple test. A second or occasionally a third chamber is added before the two tests forming the brood chamber separate and the juvenile agamonts are free to escape.

Fig. 27. Discorbis ornatissima. $a$ and $b$, multiple tests consisting of pairs of megalospheric gamonts associated in syzygy; $c$, pair of tests previously associated in syzygy which were separated before the first progamic nuclear division. The ventral walls of the two tests begin to dissolve during early gametogenesis; $d$, multiple tests containing juvenile megalospheric agamonts; $e$, more advanced stage than that shown in $d$, the opening between the two tests having been further enlarged and the juveniles ready to escape; $f$, one of a pair of excavated tests following the escape of the megalospheric agamonts. 

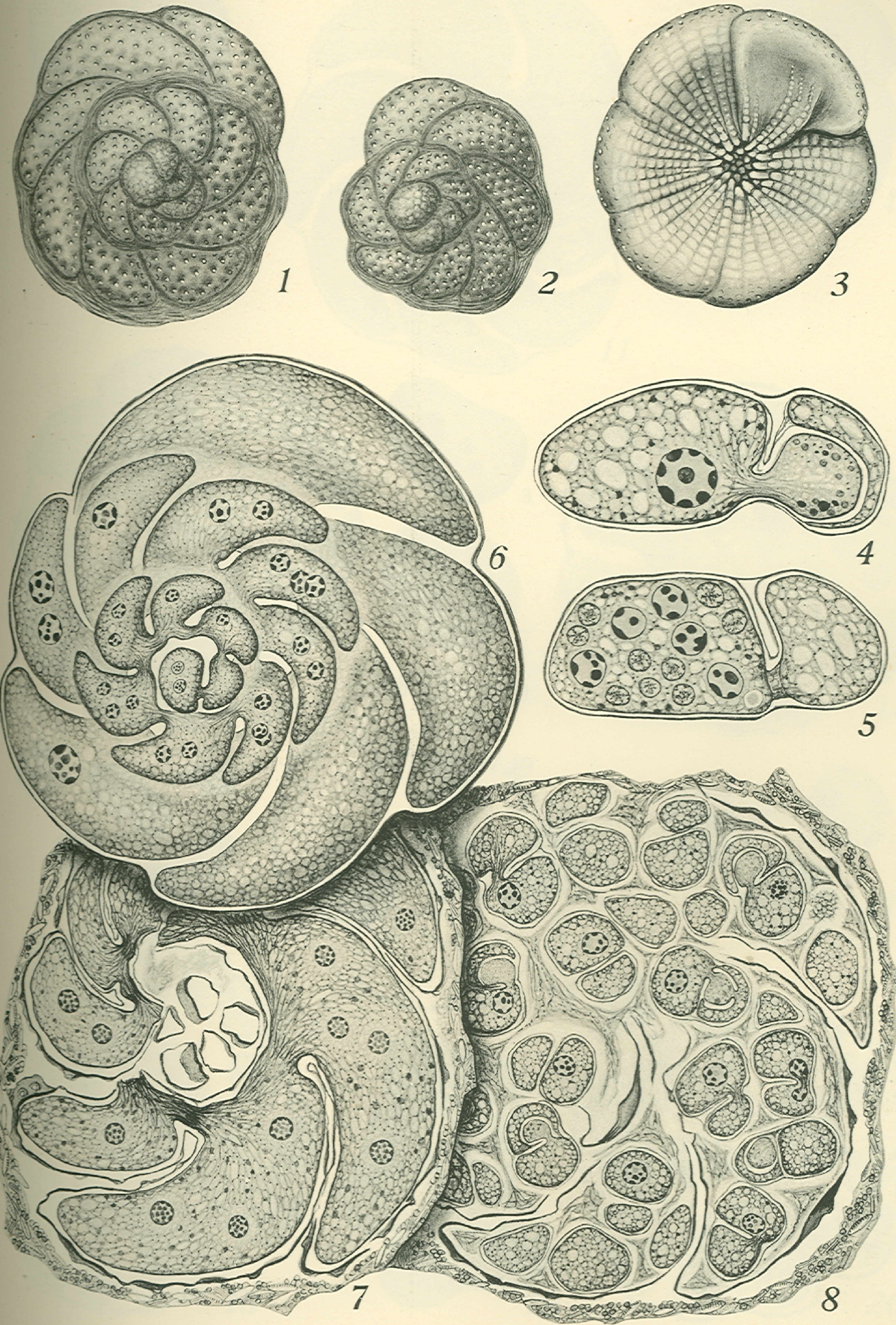

Del. E.H.M. 

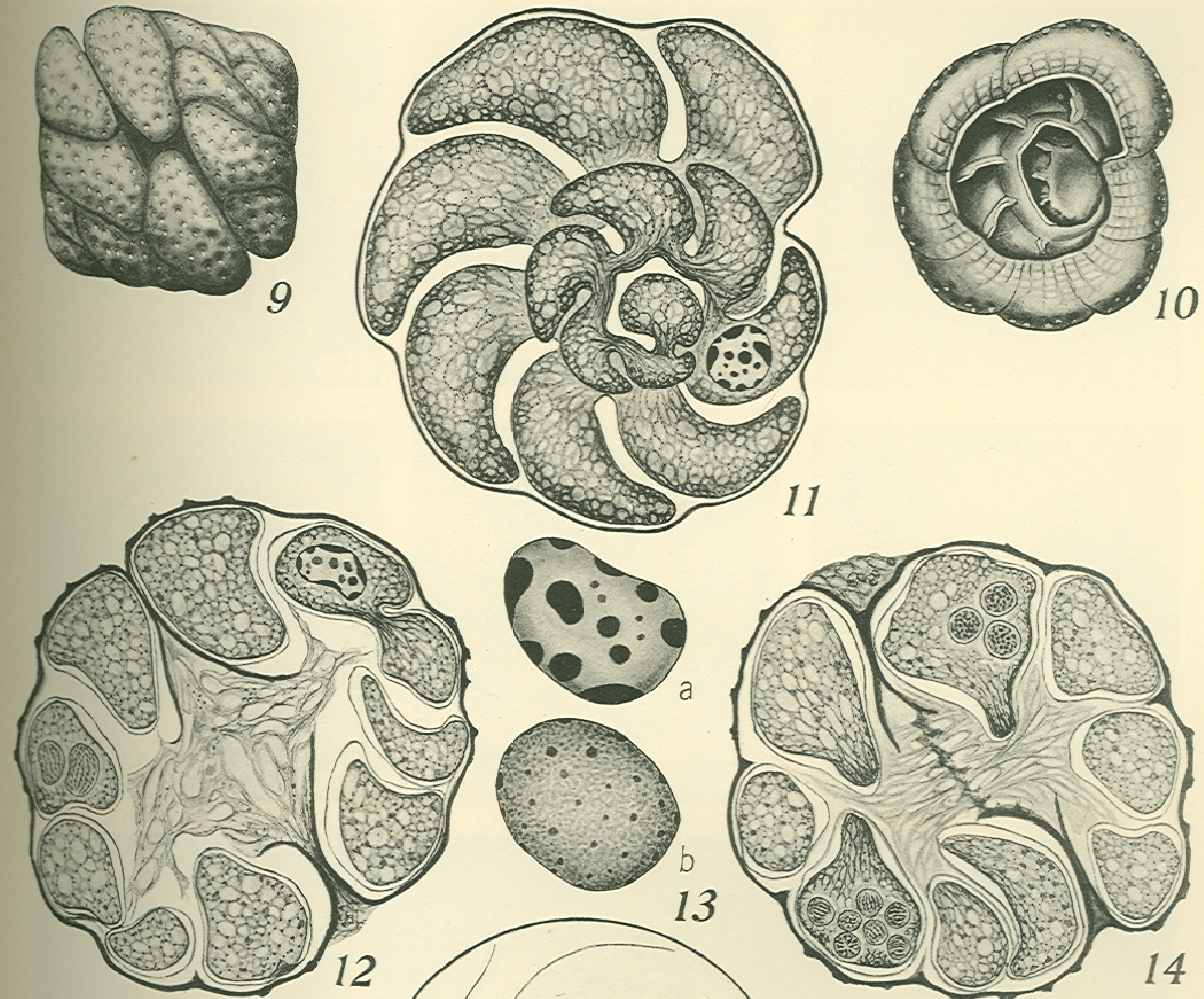

(5)
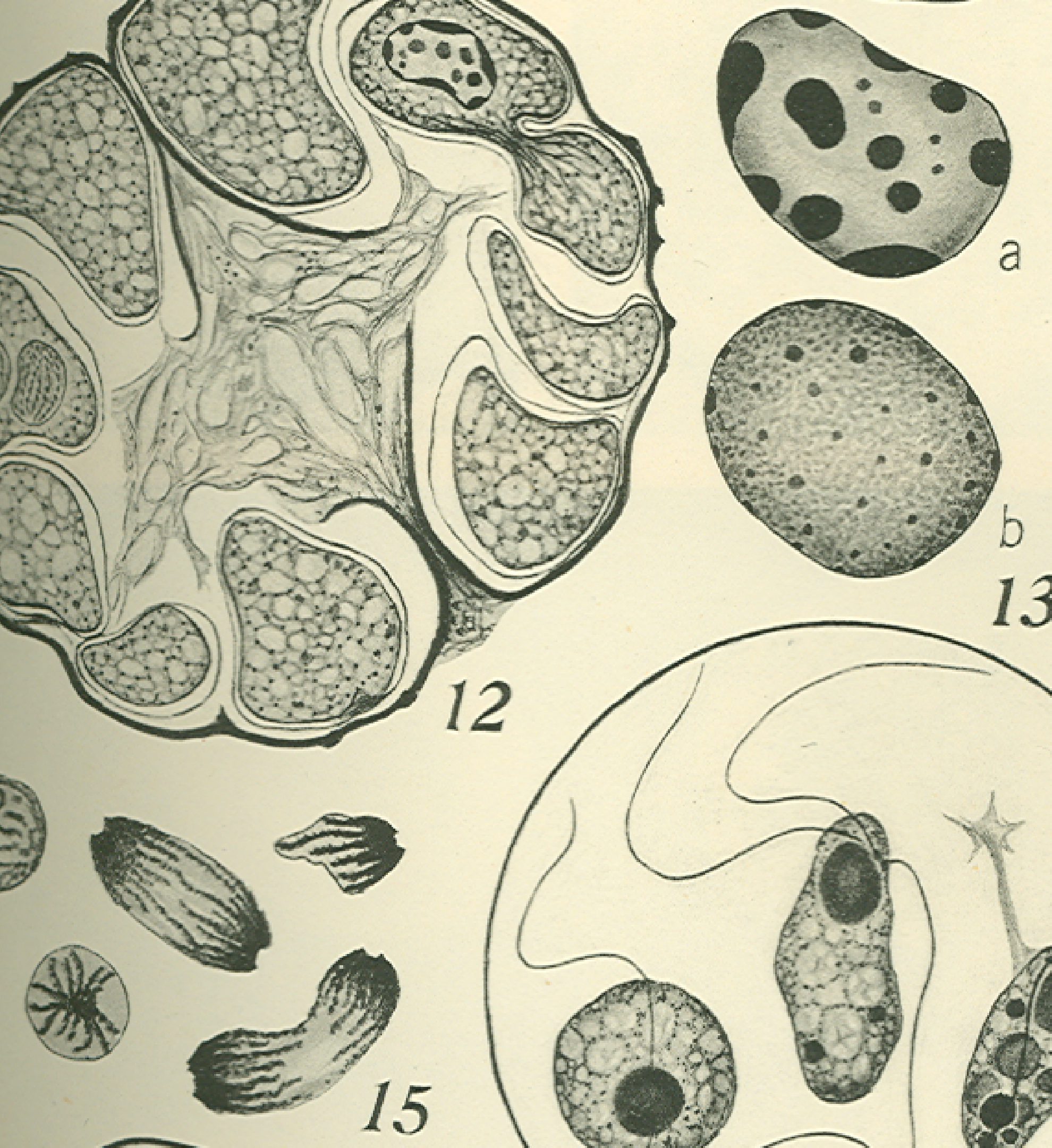

11

0
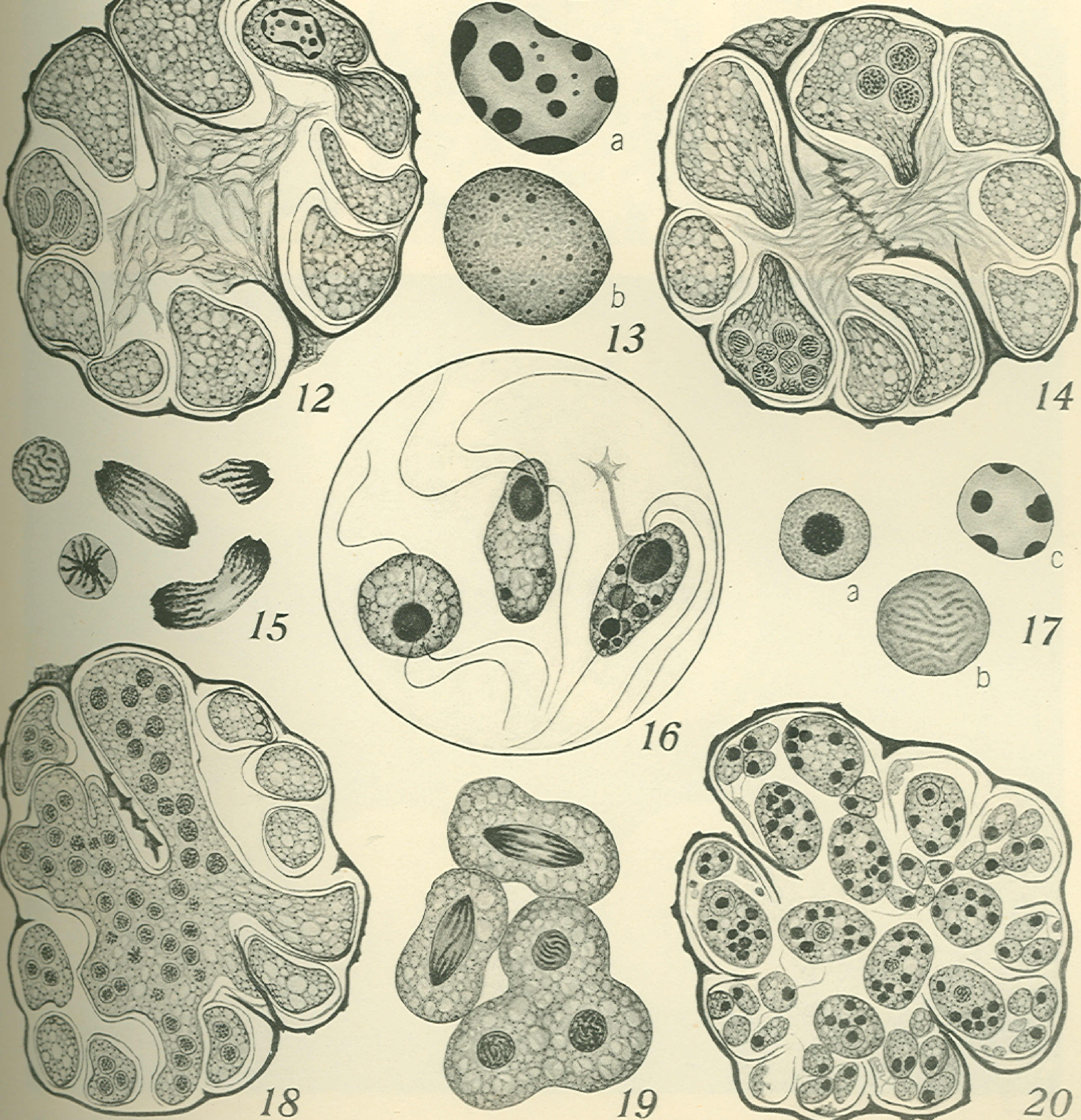

14

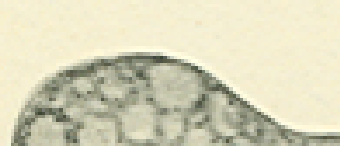

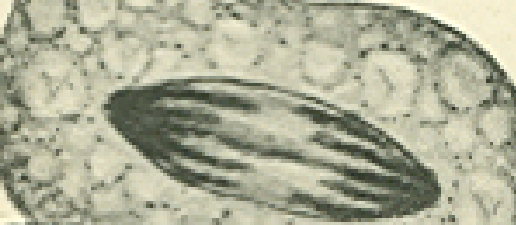

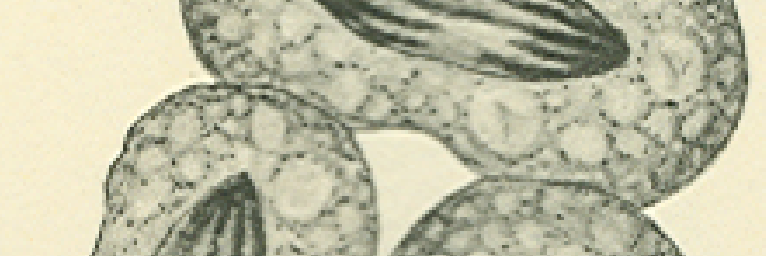

(7) $0 \times 1$

(6) $($ ) 3

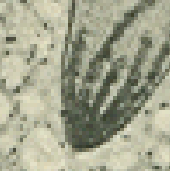

$6012 \times$

12.

19

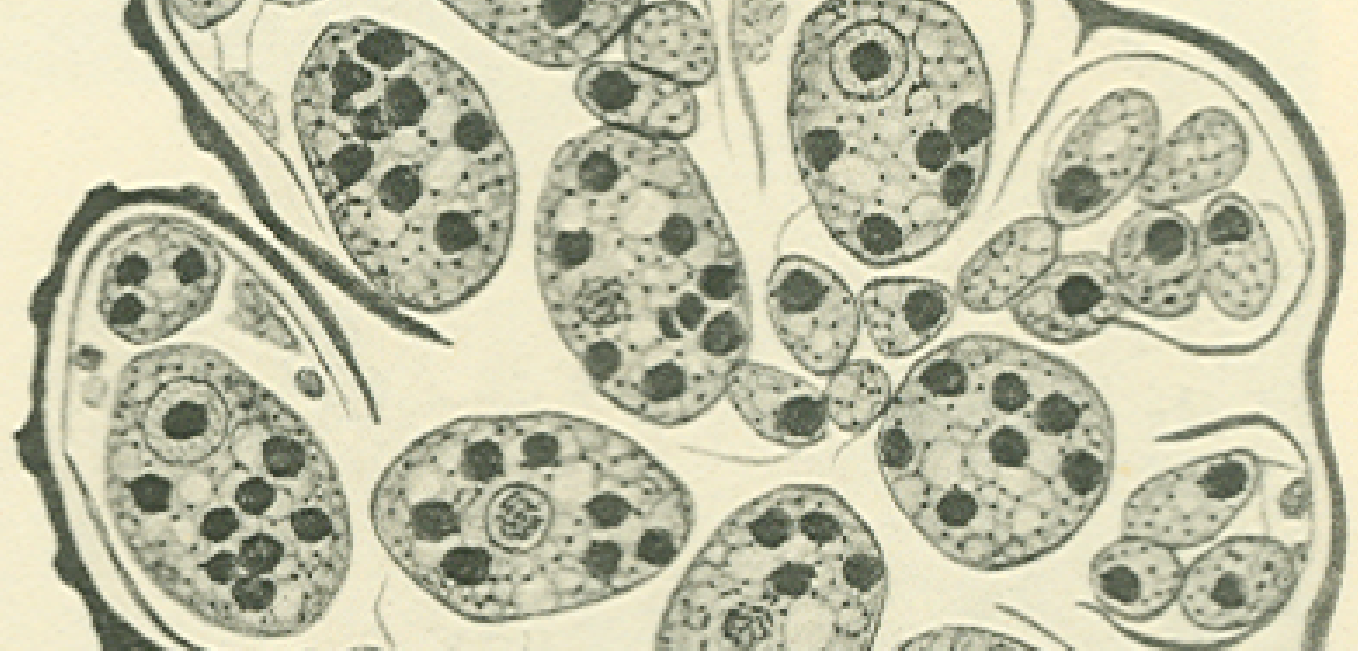

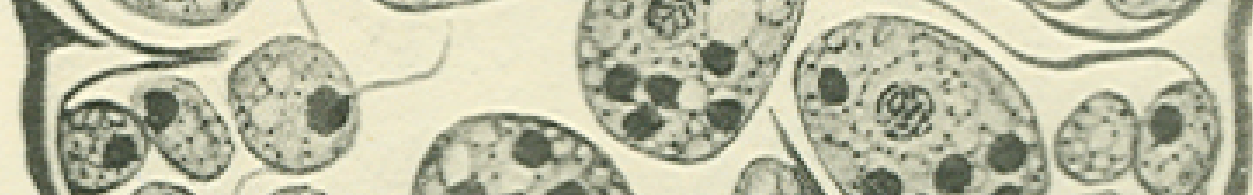

(20.9.2.

(30) 00

Del. E.H.M. 

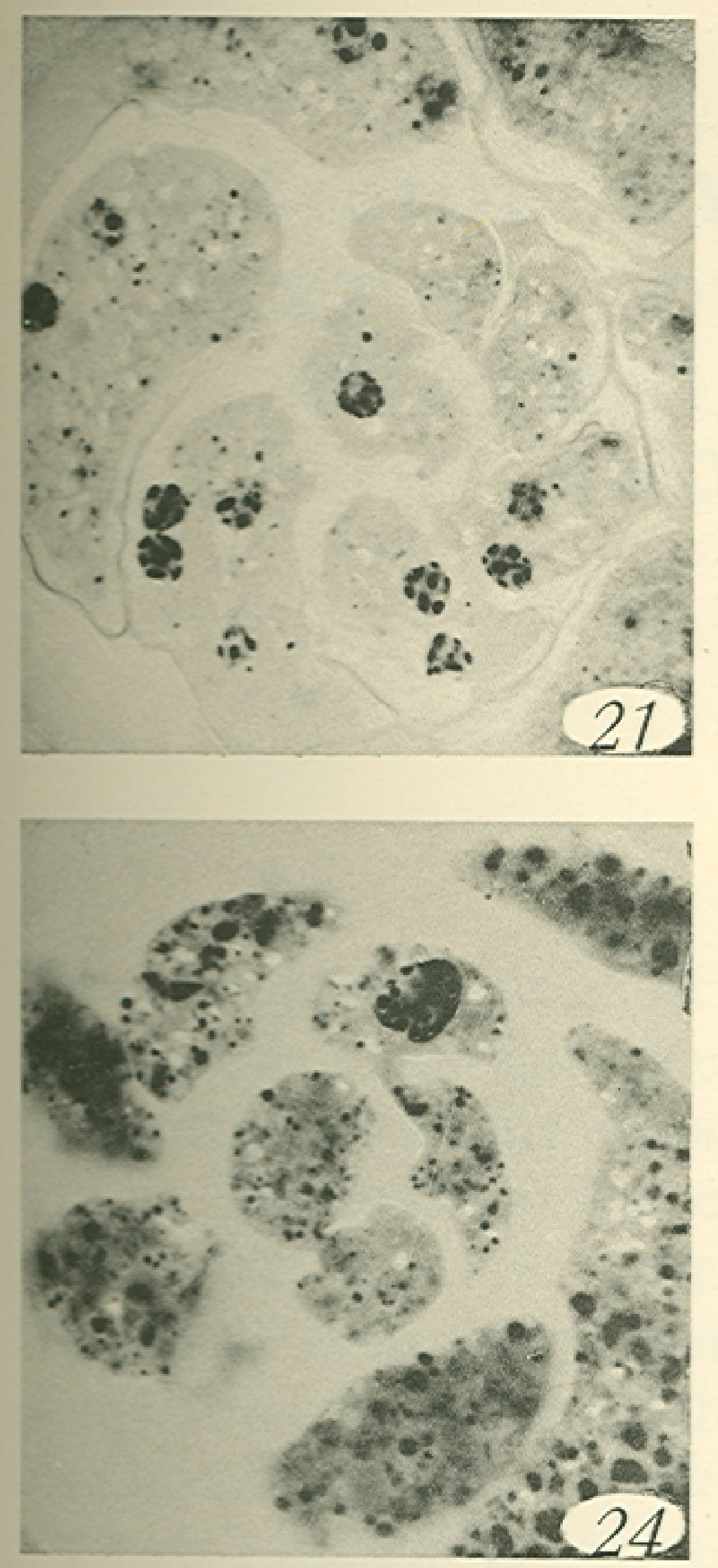
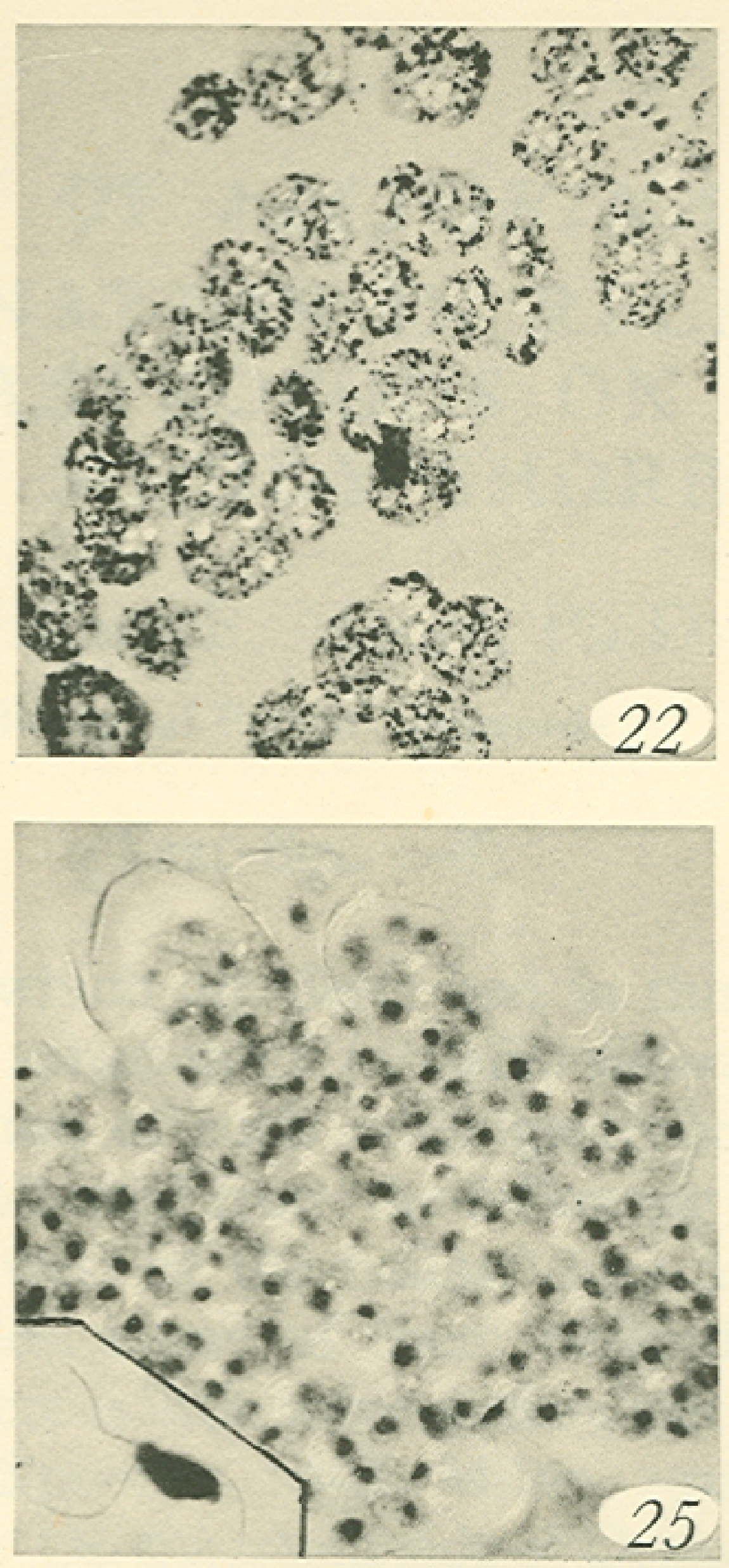
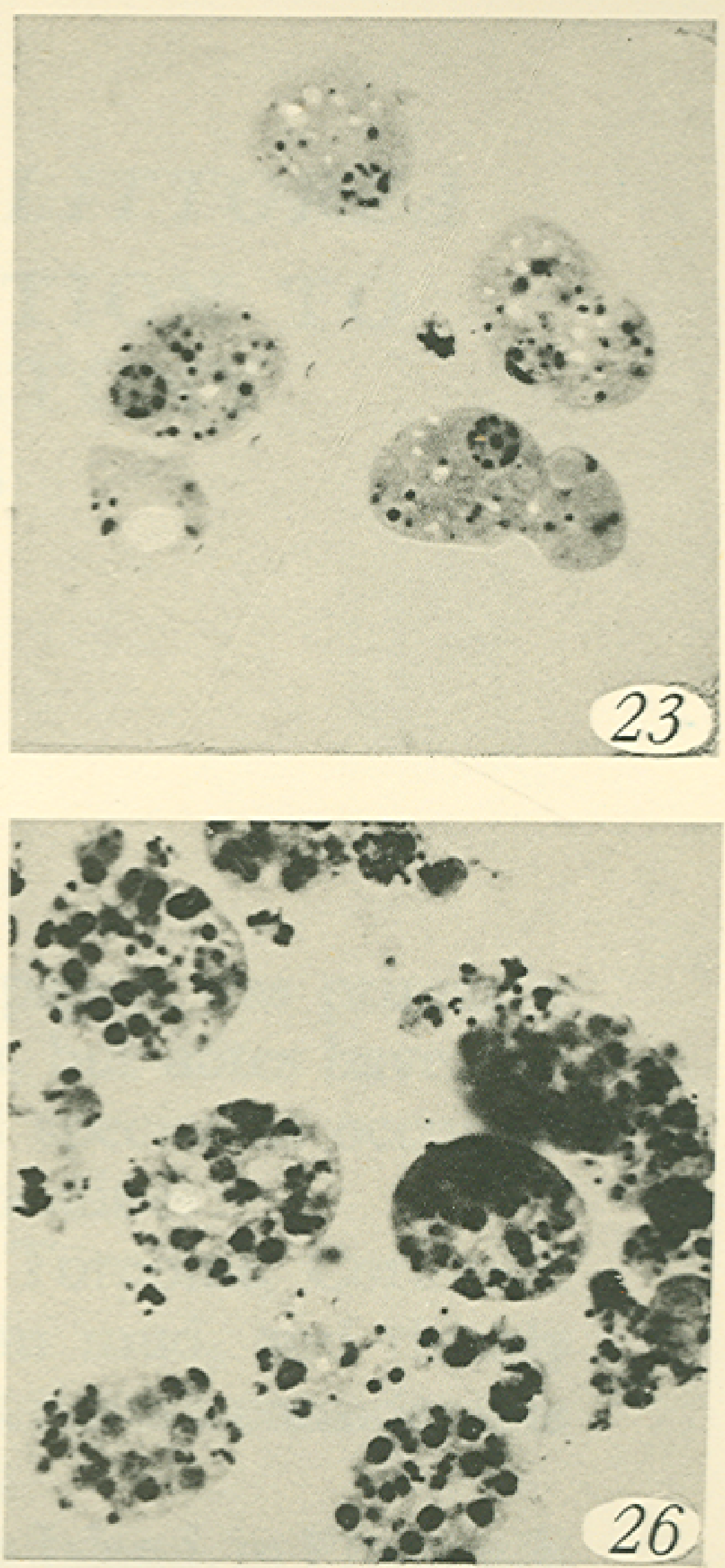

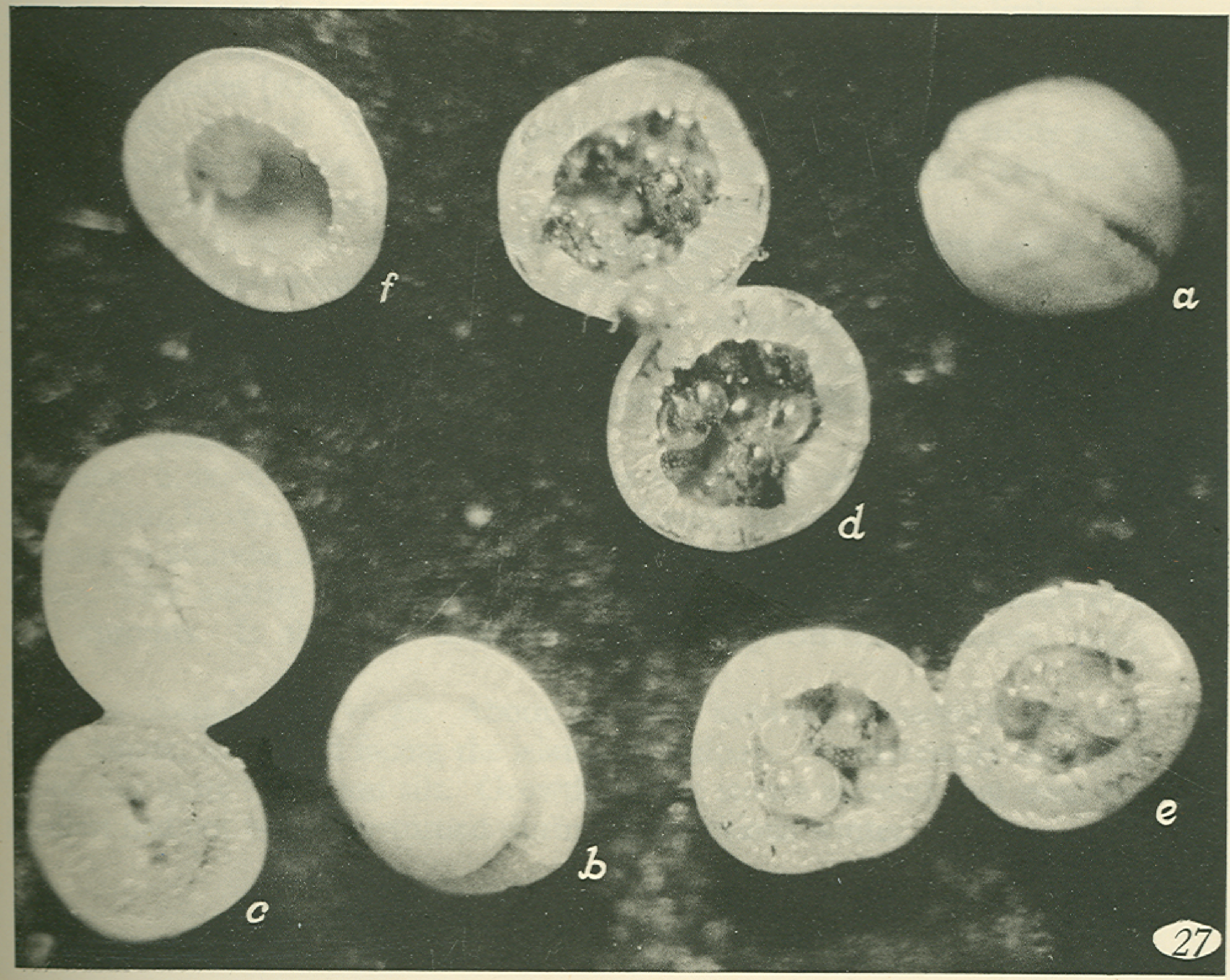

Photo. E.H.M. 